\title{
Orientações de projeto para ambiente escolar adequado a surdos e pessoas com deficiência auditiva: desenvolvimento de uma cartilha para arquitetos
}

\author{
Design guidelines for school environments suitable for the deaf and \\ the hearing impaired: development of a booklet for architects
}

MANOELA GODOY AVEIRO

Graduanda em Arquitetura e Urbanismo, Unicamp, mga.aveiro@gmail.com

ANGELA ALESSANDRA TOREZAN SILINGARDI

Arquiteta Urbanista, Especialista em Enga de Segurança do Trabalho,

angelasilingardi@gmail.com

NÚBIA BERNARDI

Arquiteta e Urbanista, Docente na Faculdade de Engenharia Civil Arquitetura e Urbanismo, Unicamp, nubiab@unicamp.br

\section{RESUMO}

Este artigo apresenta o processo de desenvolvimento de uma cartilha de orientação aos arquitetos, para ser usada como ferramenta complementar ao processo de projeto de ambiente escolar adequado ao deficiente auditivo. Considerando que é destinada a profissionais de arquitetura, a cartilha apresenta de forma direta os atributos específicos necessários para a construção de tal espaço. Ao descrever este processo, o artigo aborda o resultado de uma sequência de etapas que culminaram com a primeira versão da cartilha. Inicialmente, as atividades envolveram revisão de literatura e, em seguida, alguns estudos de caso - análise de um projeto referencial para a Universidade Gallaudet e de cartilhas existentes sobre acessibilidade. O conceito DeafSpace, desenvolvido pela Universidade Gallaudet, tem sido uma importante referência para trabalhos que envolvem acessibilidade a pessoas com deficiência auditiva. O resultado - a cartilha proposta - seleciona e incorpora vários dos conceitos identificados nas etapas preliminares de maneira lógica e sequencial. Além da linguagem textual, estes conceitos são apresentados em linguagem visual, o que contribui significativamente para seu entendimento e aplicação.

PALAVRAS-CHAVE: acessibilidade, deficiente auditivo, ambiente escolar, cartilha, orientação de projeto

\section{ABSTRACT}

This paper refers to the development process of a guidance booklet for architects, to be used as a complementary tool to the school environment design process suitable for the hearing impaired. 


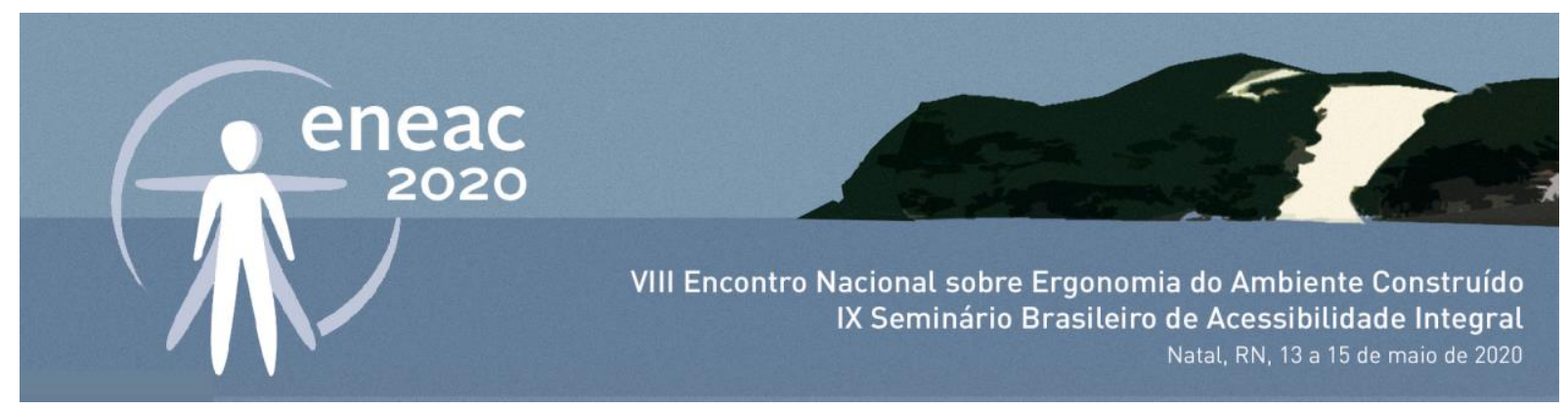

Considering that it is targeted to architecture professionals, the booklet presents, with a direct approach, the necessary requirements for the construction of such space. When describing this process, the paper addresses the result of a sequence of steps that culminated in the first version of the booklet. Initially, the activities involved literature review and, after that, some case studies - analysis of a referential project for Gallaudet University in Washington / USA and analysis of existing booklets related to sidewalks accessibility. This university developed the concept of DeafSpace and has been an important reference for works related to accessibility of deaf people. The result - the proposed booklet - selects and incorporates many of the concepts identified in the preliminary steps in a logical and sequential way. In addition to textual language, these concepts are presented in visual language, which contributes immensely to their understanding and application.

KEYWORDS: accessibility, hearing impaired, school environment, booklet, project guidance

\section{INTRODUÇÃO}

Este artigo trata do processo de elaboração de uma cartilha de orientação ao profissional de arquitetura, para ser usada como ferramenta complementar no processo de projeto de ambiente escolar adequado ao deficiente auditivo. Partindo do pressuposto que será utilizada por profissional com conhecimentos técnicos na área de engenharia e arquitetura, optou-se pela abordagem direta de atributos específicos de projeto relacionados à questão do deficiente auditivo. Isso não descarta, de forma alguma, outras questões de adequação a padrões construtivos e cumprimento de leis e normas vigentes no município, estado e país.

Além de questões inerentes a todo processo de projeto (soluções técnicas e artísticas, funções, volume, espaço, textura, luz, materiais, componentes técnicos e custos, desempenho e tecnologia construtiva) (KOWALTOWSKI et al,2011a), o projeto de ambientes de ensino adequados à formação de crianças e jovens envolve várias outras relacionadas aos processos pedagógicos de ensino e aprendizagem, percepção e apropriação do espaço construído. No caso de instituições de ensino adequadas aos deficientes auditivos, o conhecimento de suas necessidades e características influenciará diretamente a qualidade e adequação dos espaços destinados a essa comunidade. Além disso, tais espaços, quando projetados de acordo com as diretrizes de Desenho Universal, wayfinding, acessibilidade, Well Building e DeafSpace, serão também adequados e apropriados para o uso de qualquer pessoa, com necessidades específicas ou não.

Segundo Nair e Fielding (2007), salas de aula bem planejadas fazem a diferença no aprendizado. Desde que as escolas tradicionais (ou como as conhecemos) foram instituídas, a rigidez no ensino tem se refletido na rigidez do espaço das salas de aula buscando diminuir a distração e aumentar a concentração e a seriedade do ambiente. Hoje, os arquitetos sabem mais sobre como se vive e como se trabalha do que jamais souberam. Contudo, embora existam diversas discussões sobre educação humanizada, isso não está repercutindo nos espaços de aprendizado, as questões de conforto e rigidez continuam sem solução, ou as inovações não chegam a ser aplicadas em práticas cotidianas.

Diante disso, em seu artigo, Nair e Fielding (2007) apresentam preceitos para um bom projeto educacional. Mesmo sem se direcionar diretamente ao deficiente auditivo, os valores que tais preceitos incorporam nos ambientes escolares os tornam melhores e mais adequados a todos, deficientes ou não. Os autores propõem o uso de mobiliário adequado e confortável, e colocam a 


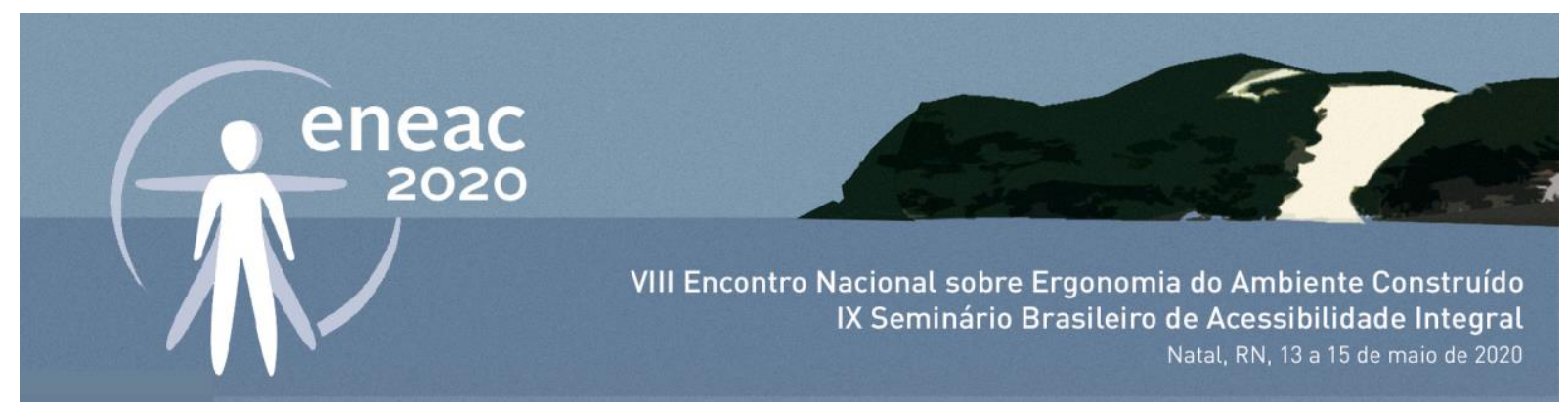

necessidade de se cuidar da ventilação/renovação do ar e do conforto acústico. Também incentivam a criação de ambientes acolhedores e áreas de convivência e estar onde os alunos e funcionários gostem de permanecer e interagir. Ressaltam a importância da criação de ambientes agradáveis e utilizáveis ao ar livre, onde há muitas oportunidades de aprendizado que muitas vezes são esquecidas. Por fim, sugerem a divisão de grandes instituições de ensino em células menores, onde os alunos possam se sentir parte do grupo, seguros e acolhidos.

Estes conceitos foram pensados como uma forma de melhorar a qualidade das instituições de ensino e do aprendizado como um todo, de forma abrangente, e podem ser percebidos em outros estudos a serem apresentados no presente trabalho, como o Well Building, o Desenho Universal e o DeafSpace, este último relacionado especificamente com o deficiente auditivo.

Complementando os fatores levantados por Nair e Fielding (2007), Fransolin et al. (2016) apresentam a importância dos aspectos sensoriais para a experiência dos surdos em um ambiente. Para os deficientes auditivos, a orientabilidade espacial está diretamente relacionada à consciência sensorial e à conexão visual do entorno, sendo a visibilidade importante tanto para as relações sociais quanto para a segurança pessoal (FRANSOLIN et al., 2016). De acordo com o artigo, o tato, a visão e o olfato constituem o principal meio de comunicação e orientabilidade do deficiente auditivo, sendo tal sensibilidade a responsável pela identidade cultural dessas pessoas. Isso porque a falta da audição afasta o deficiente auditivo do mundo distante a ele e o coloca em um mundo mais próximo.

Com isso, conclui-se que as características físicas do ambiente e sua organização, somadas aos aspectos cognitivos e percepções conscientes e inconscientes do usuário afetam a forma como o espaço é percebido e utilizado e também as interações sociais que nele ocorrem. O profissional de arquitetura deve considerar essa combinação de fatores com muito cuidado e atenção quando o usuário apresenta características específicas, como no caso dos deficientes auditivos. Há muitas questões a serem consideradas, desde o início do processo de projeto até a sua conclusão.

\section{MÉTODO}

O processo de produção do presente trabalho se debruça sobre quatro momentos distintos:

- embasamento teórico inicial, pautado em uma revisão bibliográfica de artigos sobre o tema;

- análise dos conceitos apreendidos sobre Desenho Universal através de um estudo de caso, realizado a partir do projeto do escritório Kennedy \& Violich Architecture para a Gallaudet University (segundo lugar no concurso "Shape Gallaudet");

- análise iconográfica de cartilhas já existentes sobre acessibilidade para pessoas com deficiência; e

- criação de uma cartilha, com as principais orientações de projeto e definições objetivas e diretas de necessidades, visando colaborar com o desenvolvimento de projetos adequados ao deficiente auditivo. 


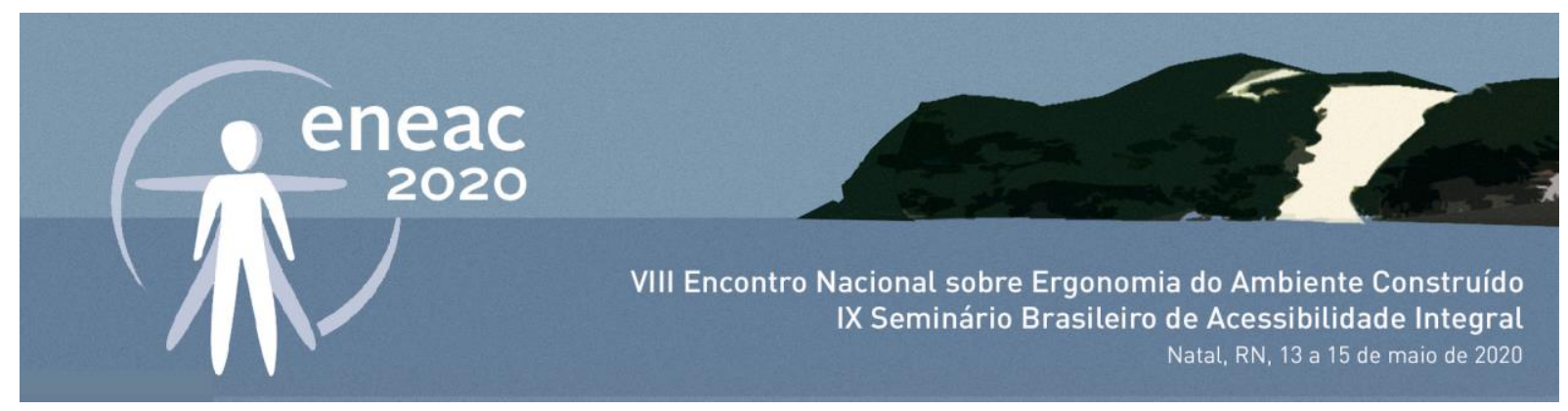

\section{CONCEITUAÇÃO TEÓRICA}

\subsection{Artigos Relevantes}

Nos estudos sobre a acessibilidade de ambientes construídos para pessoas com deficiência auditiva foram pesquisados inicialmente três artigos que contribuíram para a formação de uma base referencial para o entendimento dessa questão: A importância da ergonomia do ambiente construído nos projetos arquitetônicos - o caso dos deficientes auditivos (NEVES e NEVES, 2018), O jogo da arquitetura: discutindo a acessibilidade para surdos (FRANSOLIN et al., 2016) e A percepção de surdos como subsídio ao projeto: um estudo com o uso de maquete física (MEDEIROS e ELALI, 2018).

Mesmo apresentando abordagens diferentes, os títulos selecionados têm em comum a preocupação com a inclusão do deficiente auditivo no ambiente construído, incorporando este usuário no processo de projeto, ao qual a acessibilidade deve ser introduzida, enquanto partido desde as primeiras etapas. Neves e Neves (2018) abordam o tema de forma teórica, apontando para a importância da ergonomia e do Desenho Universal como forma de amenizar dificuldades cotidianas da vida dos surdos através de soluções projetuais. Fransolin et al. (2016), por sua vez, utilizam o conceito de DeafSpace como tema de uma dinâmica educativa aplicada a arquitetos e estudantes de arquitetura. $O$ objetivo é repensar parâmetros arquitetônicos visando a acessibilidade e interação do deficiente no espaço. Finalmente, Medeiros e Elali (2018) apresentam os resultados da experiência de envolver os deficientes auditivos no processo de projeto com a manipulação de modelos tridimensionais.

Cabe ressaltar que a metodologia DeafSpace (BAUMAN, 2010) presente nesses três artigos e nos demais artigos e teses estudados, é uma referência nas questões relacionadas à interação entre o deficiente auditivo e o ambiente construído. Envolve:

- Alcance Sensorial: visão e percepção do ambiente e do entorno, visão do outro, percepção de vibrações e sombras. Consciência espacial em 360;

- Espaço e Proximidade: espaço necessário para comunicação através do gestual e a visão do outro;

- Mobilidade e Proximidade: conhecimento e percepção dos percursos, como evitar obstáculos, colisões e, ainda, enxergar e se comunicar com o outro;

- Luz e Cor: uso correto e adequado da iluminação e das cores para facilitar a legibilidade dos ambientes, visão do outro e promover a segurança; e

- Acústica e Interferências Eletromagnéticas: equilíbrio nos tratamentos acústicos e níveis adequados de ruído e reverberação dos ambientes e conforto do deficiente auditivo.

Outros trabalhos relacionados ao ambiente escolar e ao deficiente auditivo consultados foram as teses de mestrado: What is privacy in DeafSpace? (SANGALANG, 2012), Deaf Space and the visual world - buildings that speak: an elementary school for the deaf (TSYMBAL, 2010), Articulation of deaf and hearing spaces using deaf space design guidelines: a community based participatory research with the Albuquerque sign language academy (JOHNSON, 2010) e A comfortable truth: well-planned classrooms make a difference (NAIR e FIELDING, 2007).

Em What is privacy in DeafSpace? (SANGALANG, 2012), o foco é a questão da privacidade e o ambiente ocupado pelo deficiente auditivo. Para o surdo, as questões referentes à privacidade e 


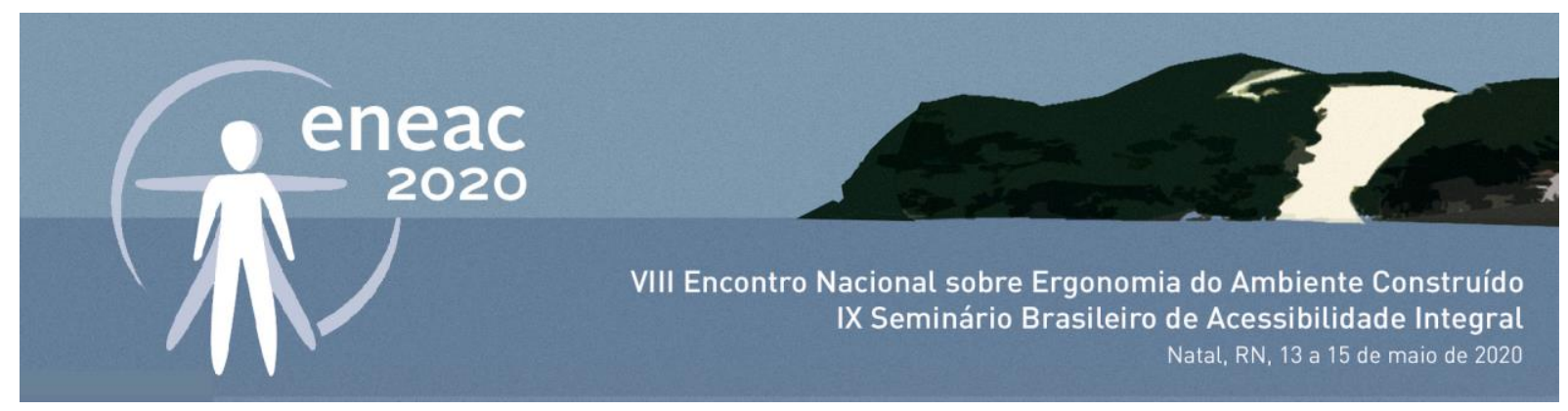

segurança implicam em uma abordagem diferente da usual. Para o não surdo, a segurança e a privacidade podem ser dados por ambientes fechados e protegidos. Já os surdos, para se sentirem seguros e bem, precisam enxergar o ambiente ao redor, porém isso leva à falta de privacidade. Os surdos se sentem isolados quando há excesso de fechamentos e expostos quando há muitas aberturas. Como equilibrar tais questões e garantir que esses dois pontos sejam contemplados nos projetos é a principal discussão deste texto.

O artigo relata análises do espaço físico, entrevistas, discussões e sugestões de alterações. Observou-se que a maioria dos participantes da pesquisa prefere ver antes de ser vista e quer saber se alguém se aproxima de sua sala antes que a pessoa entre, mas, ao mesmo tempo, não quer estar exposta aos que passam pelo corredor. Para isso, as aberturas devem permitir variações de exposição de acordo com a necessidade do ocupante da sala, caso contrário, isso será feito de forma improvisada.

Este trabalho propõe soluções práticas de projeto que podem ser aplicadas não só a ambientes de trabalho, mas também a outros tipos de espaço, atendendo a um público diversificado. Algumas das soluções propostas estão apresentadas na cartilha, objeto desta pesquisa.

Tsymbal (2010) apresenta soluções de projeto para uma escola de ensino fundamental inclusiva. As orientações baseiam-se nos princípios do DeafSpace e também em insights obtidos a partir da exploração das percepções dos surdos. Os elementos sugeridos de design e arquitetura visam inicialmente ao benefício do aluno surdo, mas será visto que beneficiam a todos os alunos.

O trabalho propõe orientações de projeto que podem ser usadas como referência para outros projetos de escolas fundamentais. Sugere inicialmente a análise de 1) forma e tamanho do terreno; 2) localização; 3) topografia e drenagem; 4) acessos e tráfego; 5) disponibilidade dos serviços públicos e 6) segurança pessoal e patrimonial. Os resultados desta análise também forneceram subsídios para algumas orientações apresentadas na cartilha, principalmente em relação à implantação e acessos.

A autora apresenta alguns exemplos de escolas onde os diversos conceitos do DeafSpace são identificados. Um dos pontos destacados é a necessidade de áreas de circulação $30 \%$ mais largas, devido ao tipo de comunicação utilizado pela pessoa surda. Quando fazem uso da língua de sinais, as pessoas precisam manter entre elas uma distância que permita a expressão do gestual e que seja adequada à visualização do outro, de eventuais obstáculos e do percurso a seguir.

Para o projeto da escola fundamental específica do estudo, a autora propõe quatro conceitos iniciais - conectividade visual, circulação, estar coletivo e sentimento de lar que se aplicam aos surdos e nãosurdos, resultando em uma escola adequada a todos. Para cada um deles são apresentadas soluções práticas que podem ser aplicadas a este e outros projetos similares.

- Conectividade Visual

- uso de transparências em peitoris, corrimãos, cantos, portas e portas com visores

- uso de enquadramentos e ângulos de visão ligando interior e exterior

- destaques para as entradas e acessos às áreas comuns

- uso de átrios internos com múltiplas funções com vista para os andares superiores e iluminação e ventilação naturais

- simetria na distribuição dos espaços facilita a localização 


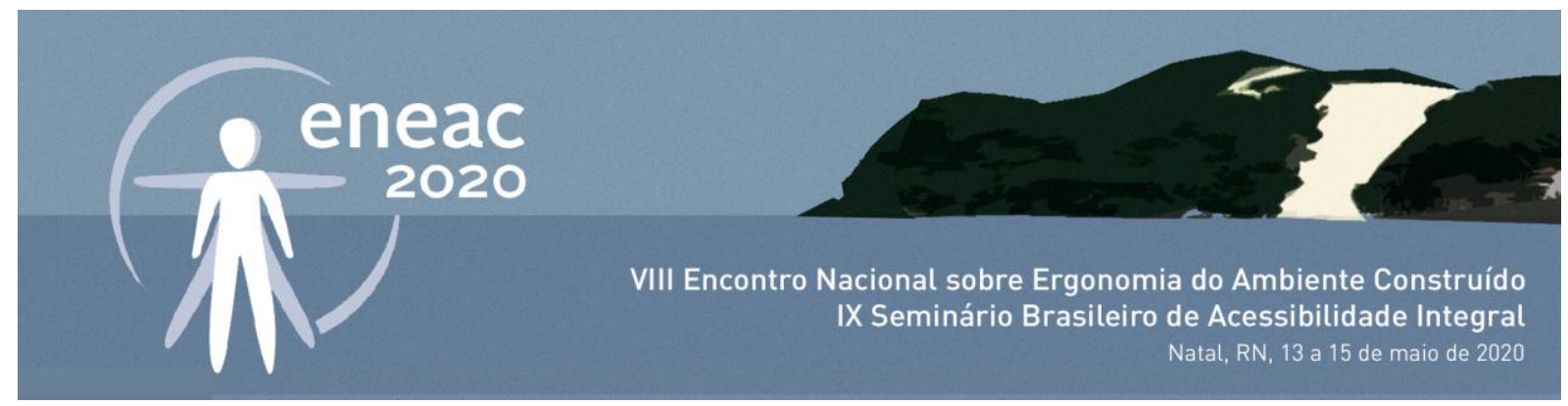

- Circulação

- uso de cantos arredondados e/ou transparentes nos caminhos e corredores

- retirada de obstáculos (colunas, mobiliário,...) dos caminhos

- caminhos $30 \%$ mais largos

- uso de texturas ou cores nos pisos e tetos definindo setores e atividades

- criação de eixos de circulação com áreas sociais nas laterais

- evitar conflitos entre eixos de circulação

- Estar coletivo

- espaços, inclusive salas de aula, devem permitir arranjos circulares e triangulares do mobiliário

- áreas comuns devem ser próximas aos caminhos para permitir agrupamentos

- Sentimento de lar

- criar pequenas comunidades dentro da instituição, com identidade visual própria, mas derivada da principal, usar cores e formas na criação da identidade.

Ressaltou-se, ainda, que, além dos conceitos do DeafSpace, questões como ergonomia, eficiência energética e tecnologia verde e acústica são essenciais para aprimorar a qualidade dos ambientes de aprendizado e torná-los adequados a todos os públicos.

Johnson (2014) busca maneiras de aprimorar o relacionamento entre surdos, deficientes auditivos e não surdos na Albuquerque Sign Language Academy (ASLA), uma escola bilíngue e multicultural, usando as premissas apresentadas pela metodologia do DeafSpace através de uma pesquisa com a equipe de funcionários majoritariamente não surda da ASLA, professores e pais de alunos.

O edifício da escola foi adaptado de um antigo edifício de escritórios e, apesar disso, ainda faltam elementos de design importantes que podem melhorar a funcionalidade do espaço da ASLA.

Usualmente, os surdos se adaptam e transformam o espaço do não surdo às suas necessidades. Nesse caso, o desafio é manter a força do espaço centrado nos valores culturais e nas necessidades do surdo e dos ouvintes de fora de seu grupo familiar.

O objetivo da ASLA é criar um ambiente de inclusão e interação entre os deficientes auditivos e os ouvintes, aumentando a sensação de pertencimento e a parceria com a comunidade e as famílias. $O$ grupo de alunos não se resume apenas aos deficientes auditivos e aos ouvintes relacionados a eles (como filhos ou irmãos de surdos), mas inclui qualquer pessoa que deseja uma educação bilíngue e inclusiva.

Como resultado da pesquisa, o grupo conseguiu apontar objetivamente algumas questões de projeto relevantes para a acessibilidade do deficiente auditivo, listadas a seguir:

- evitar reflexos nos quadros e nas telas de projeção,

- controlar a iluminação (dimmers, iluminação indireta, controle remoto) para evitar reflexos e ofuscamento sem perder a definição da imagem e da comunicação gestual,

- dividir os ambientes com vidro fosco para manter a sensação de separação e privacidade sem perder a iluminação e a visibilidade,

- aumentar o número de janelas internas para aumentar a comunicação e as conexões,

- utilizar cor nas paredes, portas, sinalização e acessos à escola, 


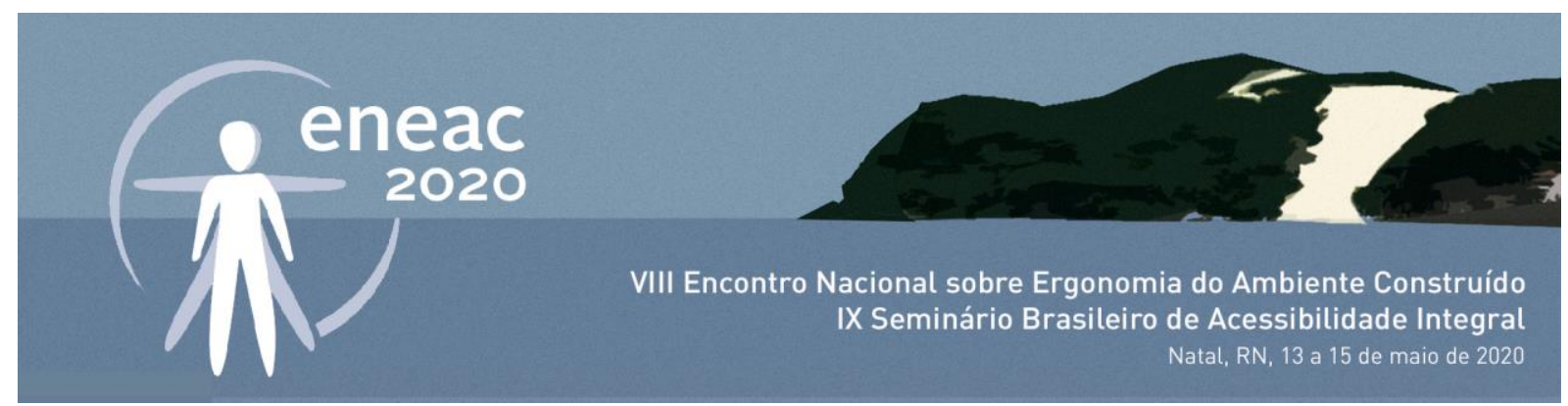

- nos cruzamentos de caminhos e corredores, usar cores, cantos arredondados, aberturas e espelhos (ensinando as crianças sobre como utilizar os espelhos durante o percurso),

- colocar aberturas nas salas de aula sem que se perca a privacidade, a segurança e a concentração dos alunos,

- usar mesas redondas, áreas comuns com arranjo circular, corredores amplos,

- diminuir pisos acarpetados e incluir trechos em madeira para permitir alguma vibração,

- criar uma sala sensorial, onde o aluno possa entender e aprender como e quando pode utilizar a vibração,

- criar quadros de sinalização escrita e luminosa nas áreas comuns e código básico de significados.

Esses pontos citados são de grande importância para a definição de um projeto acessível ao surdo. Além disso, algumas particularidades e questões específicas do usuário também foram levantadas pelos entrevistados, o que demonstra a importância de sua participação nas definições de projeto.

\subsection{Estudo de Caso - Projeto para Universidade Gallaudet, Washington/EUA}

Nessa etapa do trabalho, foi realizada uma análise de projeto referencial na questão da acessibilidade do deficiente auditivo. O projeto estudado foi a proposta do escritório Kennedy \& Violich Architecture (KVA) para o concurso "Shape Gallaudet", realizado em 2016 pela Universidade Gallaudet em Washington, EUA (https://competitions.malcolmreading.com/gallaudet/competition). A universidade é o berço da Metodologia DeafSpace e referência nas questões de acessibilidade do deficiente auditivo. O projeto do KVA ficou em segundo lugar naquele certame. A seleção deste projeto para o estudo referencial (e não o que ficou em $1^{\circ}$ lugar) justifica-se pela boa qualidade descritiva das soluções arquitetônicas apresentadas pela equipe do KVA, o que permitiu uma análise bastante elucidativa sobre as decisões adotadas no projeto.

O projeto em análise tem como princípios alguns conceitos iniciais. Em primeiro lugar, deve promover o sucesso do aluno surdo, através de ambientes de moradia e trabalho conectados, espaços de co-working e start ups, do teatro black box (um laboratório para a comunicação gestual) e do jardim central, onde devem ser explorados o conforto e as experiências sensoriais. Além disso, deve produzir um ambiente favorável à língua de sinais, com rotas legíveis e estimulantes, conexões visuais, pontos de convivência e wayfinding assertivo. Deve ter um design adequado aos conceitos do DeafSpace, focado também nos princípios de Desenho Universal e Well Building. Por fim, o conjunto deve ser coerente com a identidade da universidade e fazer dela um destino cultural.

O edifício proposto teria uso misto - moradia e trabalho, teatro, área de comércio e oficinas de criação adequadas à comunidade surda e voltadas à cidade. Desde a implantação, as proporções dos edifícios, a distância e os ângulos entre eles e os espaços vazios permitem uma visualização à distância, o que facilita o entendimento do entorno e a própria localização espacial. Contrariando a trama comum ortogonal, a entrada, localizada mais ao fundo, ganha destaque e fica visível para quem vem pela rua.

O conjunto é pensado para criar eixos de visualização clara entre ambientes externos e internos, por meio de aberturas e transparências. Esta relação é válida para os limites internos da universidade, entre o interior dos edifícios e os jardins, e também para o ambiente urbano em que se encontra, explorando o partido de que a universidade deveria se misturar à cidade. Os eixos de circulação entre os espaços são livres de barreiras visuais e os espaços são amplos, o que facilita a compreensão 


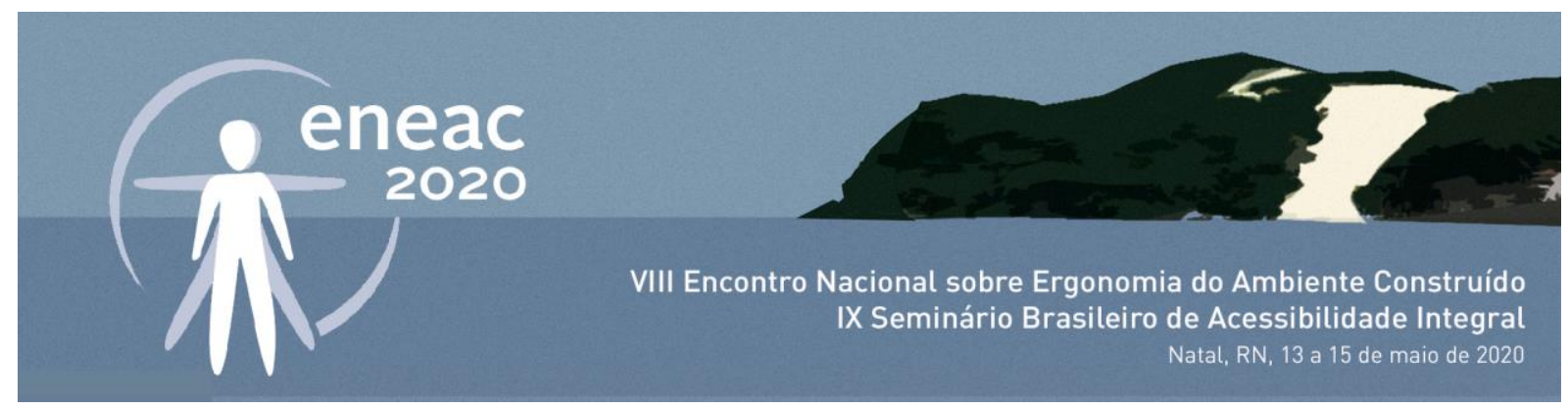

do espaço e do caminho a seguir. Fazem a conexão direta entre as grandes áreas de estar e convivência, sem esquinas e barreiras visuais.

Os conceitos de Well Building ficam evidenciados pela preocupação dos arquitetos em articular uma rotina diária para os estudantes da universidade dentro dos edifícios projetados. Assim, destaca-se a orientação das janelas dos dormitórios, de modo a possibilitar a entrada de iluminação natural pela manhã para facilitar o despertar, a criação de espaços de convivência flexíveis, que estimulam as interações entre as pessoas e possibilitam organizações diferentes que facilitam a comunicação, e o projeto de espaços que estimulam a atividade física entre seus usuários.

Os conceitos do DeafSpace, por sua vez, são pontuados através de soluções mais genéricas, porém muito bem ilustradas. Destaca-se a iluminação indireta e o controle da luz natural e do ofuscamento, o controle de ruídos, reverberações e intervenções sonoras e os espaços amplos, flexíveis, com eixos de visão e circulação desobstruídos e favoráveis à comunicação.

\subsection{Análise Iconográfica de Cartilhas Existentes}

Outra etapa do trabalho foi a análise do Guia Prático para a Construção de Calçadas do CREA-BA e da ABCP - Associação Brasileira de Concreto Portland, e do Manual de Acessibilidade da Prefeitura Municipal de Florianópolis e do IPUF - Instituto de Planejamento Urbano de Florianópolis. A análise crítica dos elementos destes guias contribuiu para a formação de um conjunto de elementos básicos que devem constar de uma cartilha, noções de como apresentar textos e imagens e de como trabalhar ideias diferentes com mesma linguagem visual de forma acessível ao profissional e ao leigo.

A análise realizada nesta fase do trabalho teve como base os elementos da iconografia, divididos entre as etapas de indexação, análise pré-iconográfica, onde foram incluídos filtros conceituais baseados nas categorias de acessibilidade Sassaki (2009), análise iconológica e crítica. O principal objeto de análise foram as imagens e figuras, organizadas e classificadas individualmente em tabelas de acordo com os critérios de cada etapa.

A etapa de indexação evidenciou a importância da presença de elementos como título, subtítulo, autores, ilustradores e outras pessoas envolvidas na produção, data de publicação, apoios e patrocínios, dentre outras informações. A descrição clara de tais elementos é essencial, tanto como forma de documentar e credibilizar o trabalho realizado, quanto para compreender possíveis interesses ligados ao apoio e patrocínio envolvidos.

Em seguida, a etapa de descrição pré-iconográfica classifica as imagens quanto ao número de elementos humanos presentes, o ambiente apresentado, o tipo de uso, o traço, cor(es) predominante(s), os volumes presentes e as qualidades expressionais identificadas. Esta análise deixa clara a presença ou ausência de uma identidade visual comum entre as imagens e figuras presentes. Nota-se que a identidade e coesão visual entre as imagens colaboram para a compreensão do conteúdo da cartilha de forma global.

As imagens foram analisadas quanto aos filtros conceituais de acessibilidade, seguindo a categorização de Sassaki (2009): acessibilidade metodológica, arquitetônica, discriminatória, programática, comunicacional, atitudinal e instrumental; quanto às deficiências tratadas (física, visual, auditiva, intelectual ou múltipla) (BRASIL, 2004) e quanto às dificuldades (idosos, gestantes, lactantes, crianças, dificuldade de locomoção, sobrepeso). 


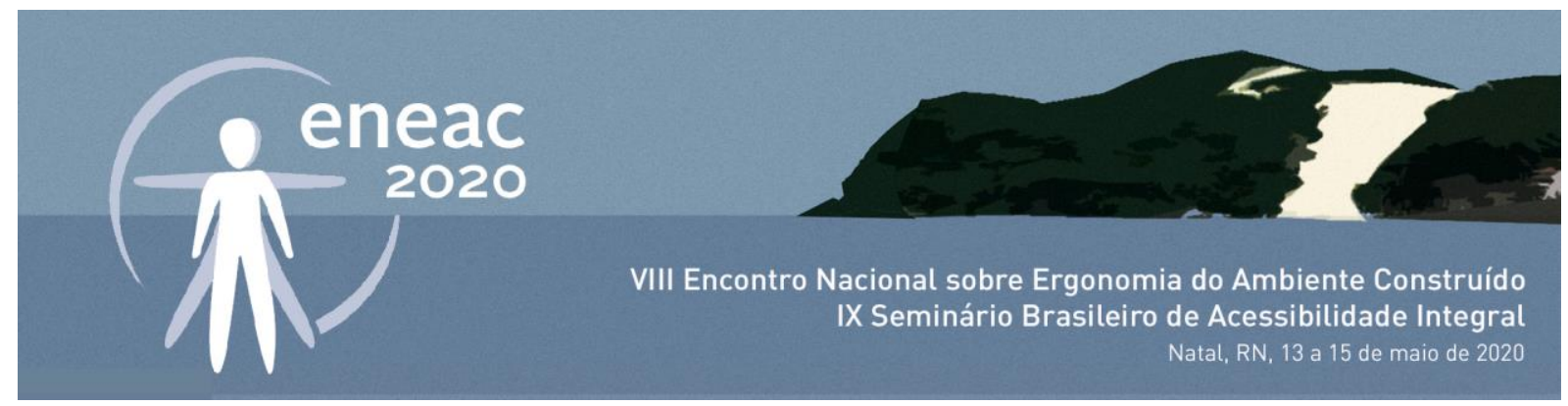

A seguir, a etapa de análise iconológica constitui uma investigação temporal do contexto de publicação da cartilha e se determinados eventos ou ocorrências podem ter influenciado o seu conteúdo. A objetividade das informações não deve ser comprometida por qualquer evento paralelo. Contudo, sabe-se que alguma ênfase pode ser dada a determinado tema diante da ocorrência, por exemplo, da publicação de alguma nova legislação, e a compreensão dessa influência pode ser importante para a interpretação da cartilha.

Por fim, a análise crítica dessa etapa do trabalho deixa claro a importância da composição gráfica da cartilha para a compreensão e para a credibilidade do conteúdo que ela transmite. A linguagem visual, especialmente no campo da arquitetura, é indispensável para o entendimento da linguagem textual. Por isso, figuras e imagens devem ser selecionadas e distribuídas de forma coesa, preferencialmente tratadas de forma a transmitir o conteúdo por meio de uma linguagem homogênea e combinadas a legendas adequadas.

\section{RESULTADOS}

\subsection{Elaboração e Produção da Cartilha}

A elaboração da "Cartilha de Acessibilidade para Deficientes Auditivos em Ambiente Escolar: orientações para arquitetos" visa colaborar e orientar, de forma complementar à legislação existente e a outras questões de ergonomia e padrões construtivos, a produção de ambientes acessíveis a este público em específico, considerando suas necessidades e particularidades. Para alcançar este objetivo, optou-se por restringir as orientações a um ambiente de uso determinado, não havendo pretensão de criarem-se, neste trabalho, regras universais para adequação dos espaços.

Assim, a primeira escolha desta etapa foi a de restringir o escopo de aplicação do produto (Figuras 01 e 02). A opção pelo ambiente escolar deve-se à literatura acessível sobre o tema: além de o estudo de caso ter sido realizado sobre uma universidade, já encaminhando as soluções para um ambiente de estudos, muitas diretrizes sugeridas na cartilha seguem os conceitos apresentados em Kowaltowski (2011b). Além disso, para o embasamento teórico do conteúdo produzido, foram pesquisados textos complementares que fazem referência, mesmo que indiretamente, aos conceitos de Well Building e DeafSpace no ambiente escolar, apresentados no item 3.1 do presente trabalho.

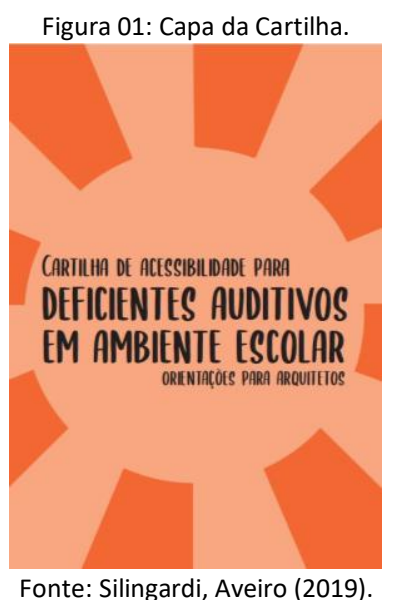



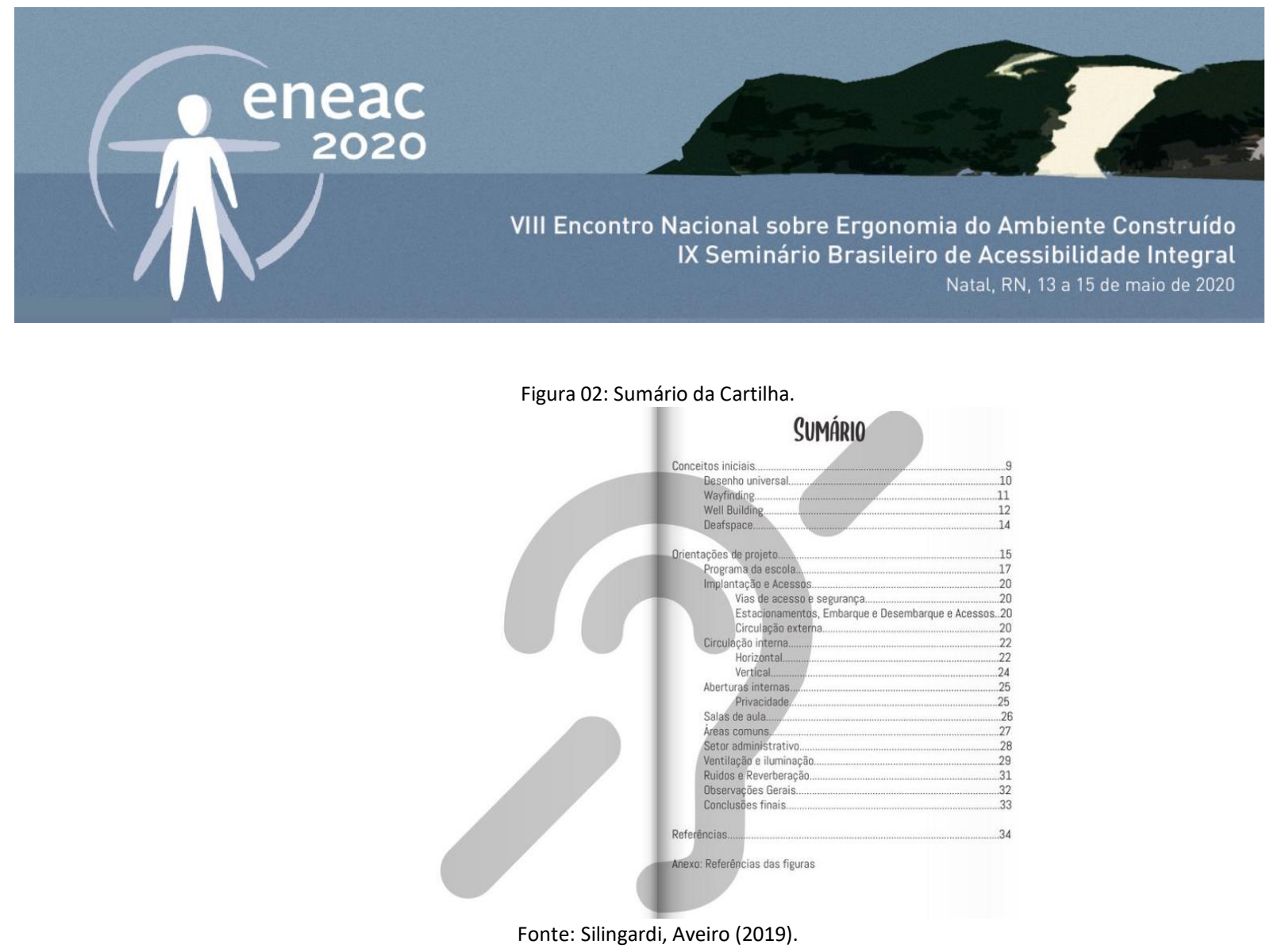

Todo o conteúdo apresentado na cartilha tem como princípios básicos os conceitos de Desenho Universal, wayfinding, Well Building e DeafSpace. Por isso, embora seja destinada a profissionais da arquitetura, e não ao público leigo, a cartilha conta com uma primeira seção de Conceitos Iniciais e Orientações de Projeto, que apresenta rapidamente tais termos e seus principais pontos, presumindo que não sejam amplamente difundidos mesmo no ambiente profissional (Figuras $03 \mathrm{e}$ 04). Uma parte importante da cartilha refere-se às Orientações de Projeto. Este bloco foi dividido entre os principais elementos/ambientes de uma escola, definidos de acordo com consulta ao programa básico de uma escola segundo o FNDE (2009). Neste capítulo são apresentados também um Fluxograma e orientações importantes sobre Implantação e Acessos.

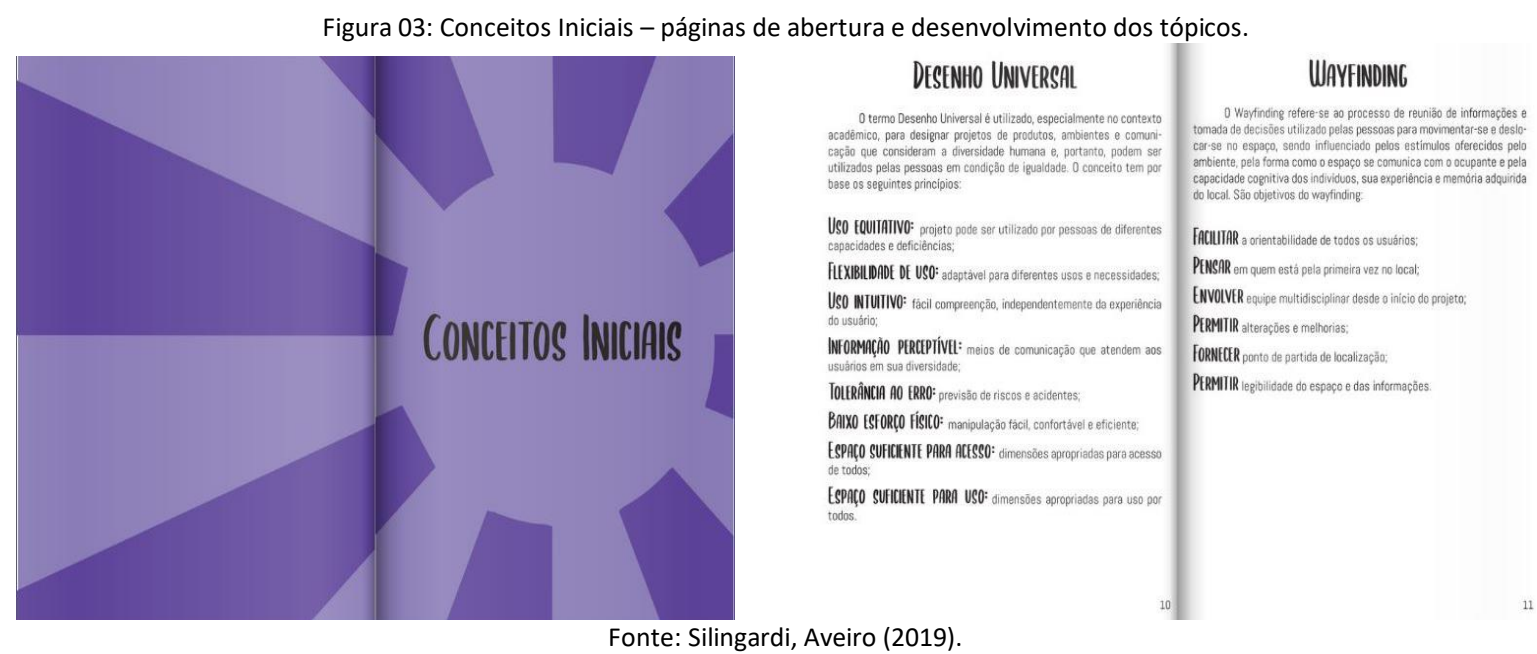




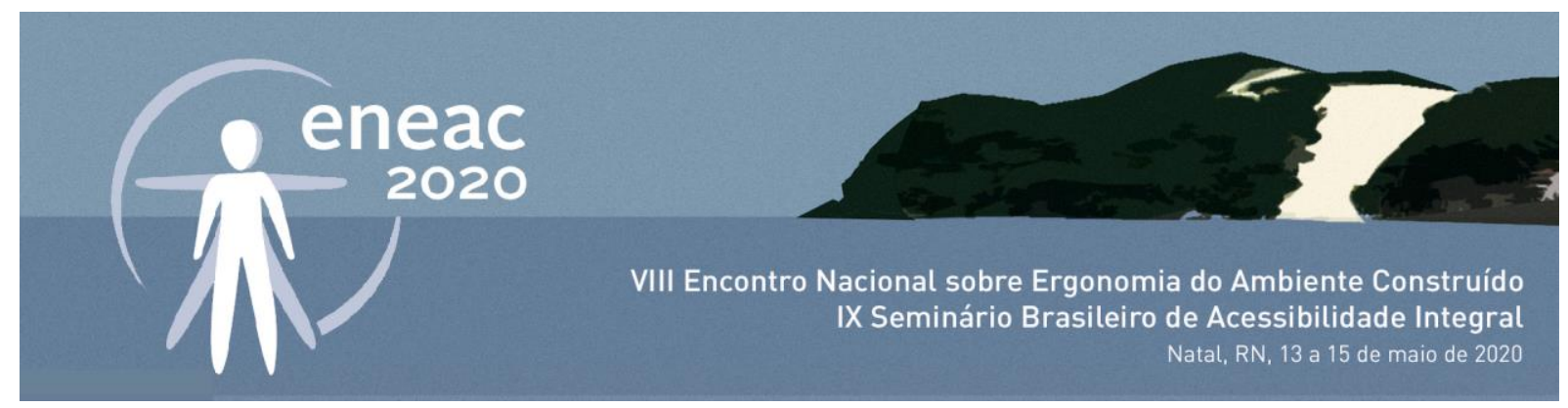

Figura 04: Orientações de Projeto - páginas de abertura e desenvolvimento dos tópicos.

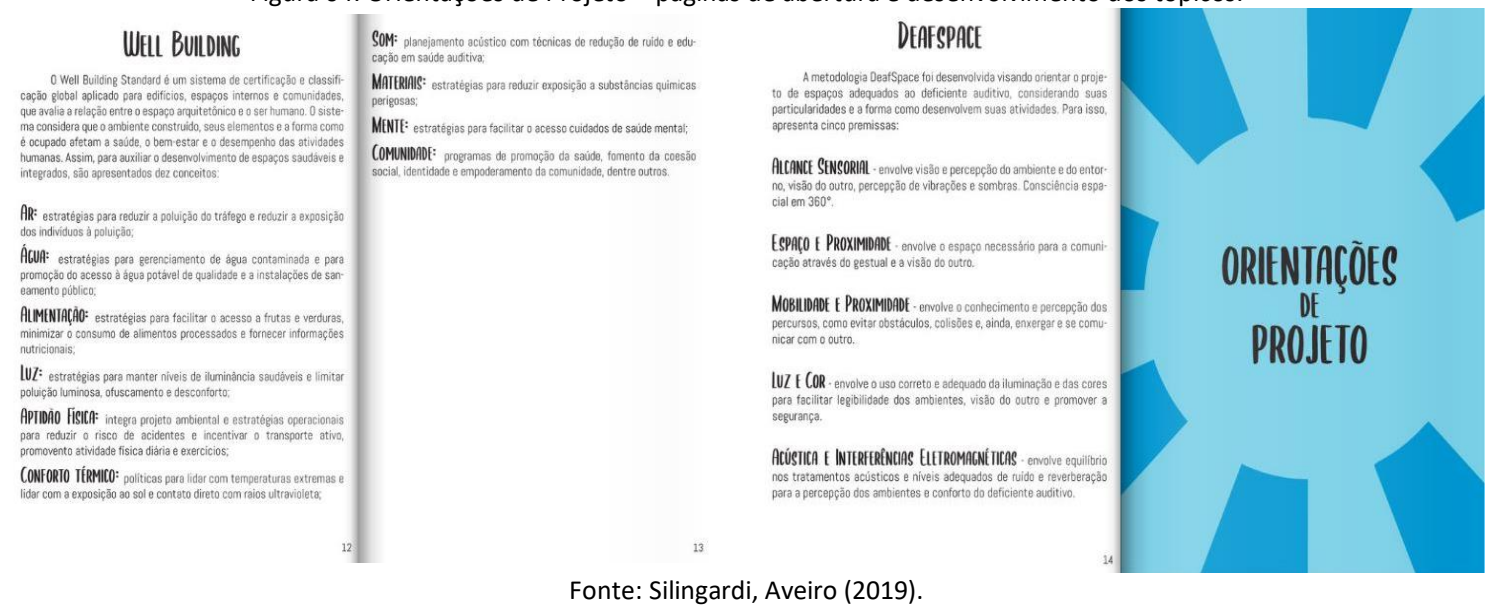

Quanto à divisão de capítulos, a cartilha contempla, além dos Conceitos Iniciais e Orientações de Projeto, os seguintes tópicos: Implantação e acessos à escola (Vias de acesso e segurança; Estacionamentos, embarque, desembarque e acessos (Figura 05); e Circulação externa); Circulação interna (Horizontal e Vertical) (Figuras 06 e 07); Aberturas internas (e Privacidade) (Figuras 08 e 09); Salas de Aula; Áreas Comuns; Setor Administrativo; Ventilação e lluminação; Ruídos e Reverberação; Observações Gerais; e Considerações Finais.

Figura 05: Orientações para áreas de estacionamento, embarque e desembarque e acessos externos.
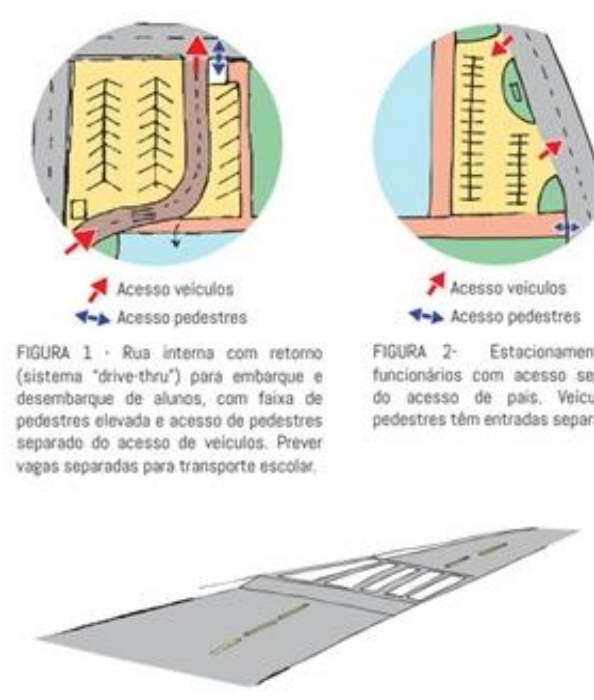

FIGURA 4 - Facia elevada para travessia de pedestres - croqui sem escala

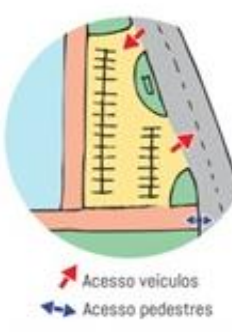

FIGURA 2. Estacionamento de funcionsrios com acesso separado 60 acesso de pase veiculos pedestres têm entradas separadas.

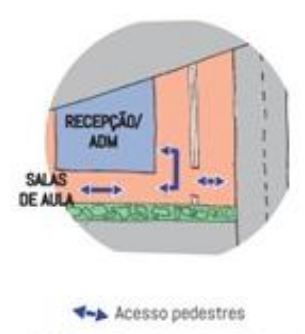

PGura 3 . Acesso único de pedestres deve ser dividido interna mente atraves de sinalizaçă adequada.

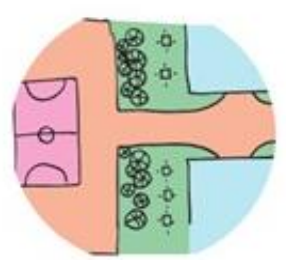

FIGURA 5. Uso de vegetaçio para reduair a interferencia de nido das quadras/pátios/ruas nas salas de quadr

Fonte: Silingardi, Aveiro (2019). 


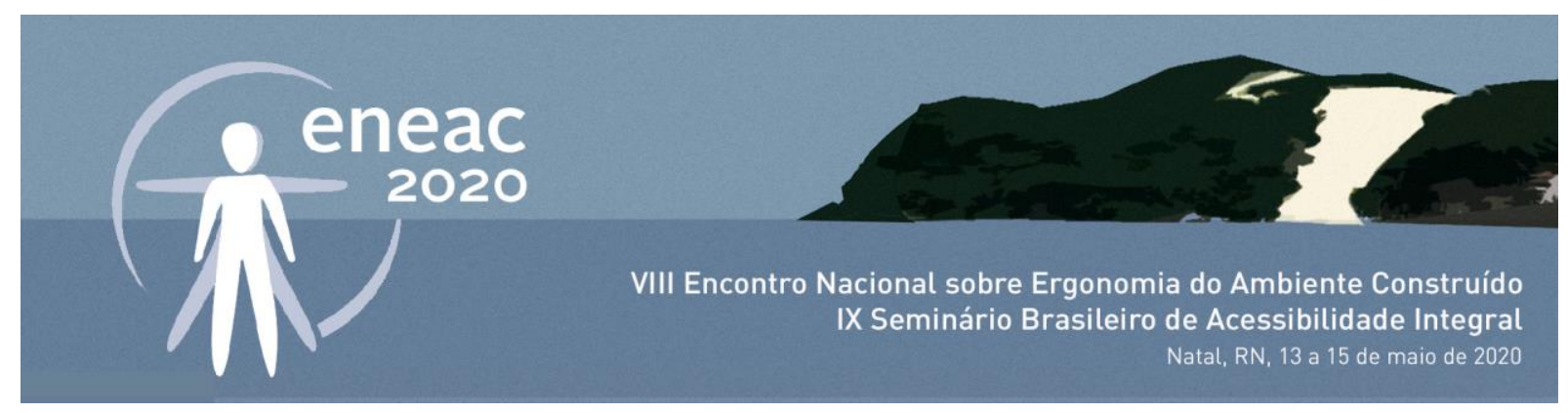

Figura 06: Orientações para espaços de circulação interna e eixos de visualização.

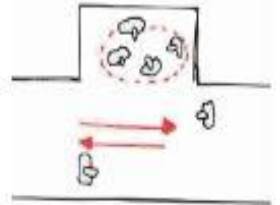

FIGURA 14 - Disposiçã̃o de nichos nos corredores favorece circulção desimpedida

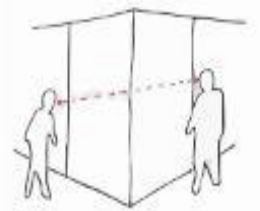

FIGURA 15 - Paredes dispostas com ângulo de $90^{2}$ prejudicam a visibilidade. Sugere-se cantos arredondados para os ambientes internos.

Fonte: modificado de Sangalang (2012) e Dangermond Keane Architecture (sem data).

Figura 07: Orientações para espaços de circulação interna e eixos de visualização.

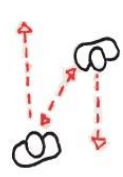

FIGURA 7 - Eixos de visão livres entre os pedestres

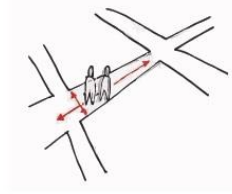

FIGURA 8 - Calçadas largas e circulação desimpedida

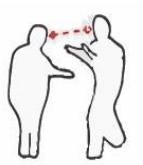

FIGURA 10 - Circulação deve permitir contato visua

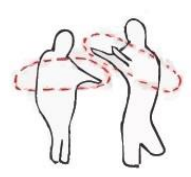

FIGURA 11 - Circulação deve permitir expressão gestual

Fonte: modificado de Dangermond Keane Architecture (sem data).

Figura 08: Aberturas internas e eixos de visualização.

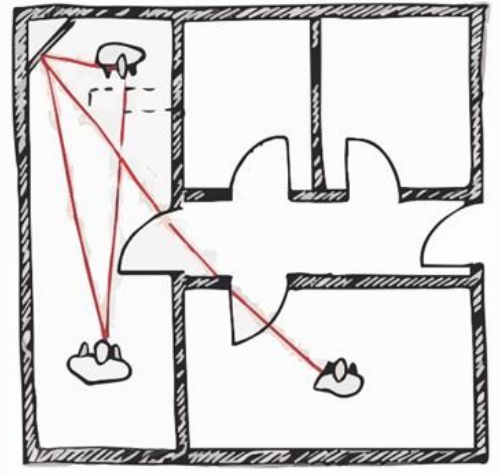

FIGURA 18 - Enquanto aberturas possibilitam conexão visual entre ambientes, a disposição de superficies espelhadas amplifica a experiência sensorial

Fonte: modificado de de Sangalang (2012).

Todos os itens apresentam uma parte textual, acompanhada de figuras que explicam os conceitos abordados. As figuras utilizadas na cartilha foram adaptadas de imagens encontradas ao longo das referências. Para a sua produção, contudo, foram modificadas de modo a criar uma identidade única e comum a todas, tornando a linguagem visual mais homogênea e de fácil compreensão. Também com esse objetivo, as cores escolhidas buscam evidenciar com clareza os elementos destacados pelo texto, e os traços são simplificados, bem como a presença dos volumes e elementos humanos, evitando conflito de informações. 


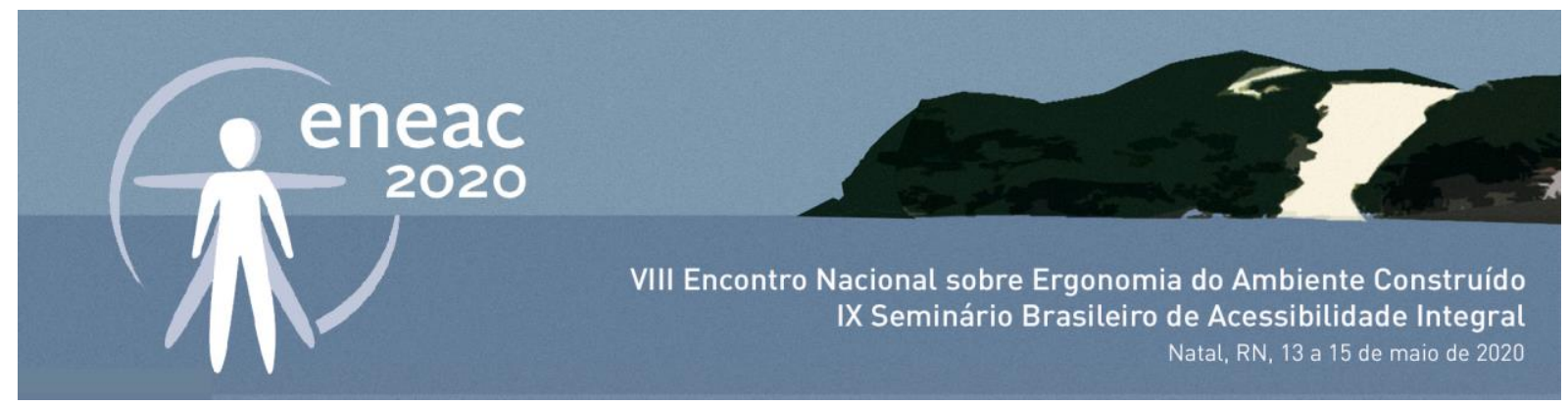

Em todos os espaços são apresentadas soluções arquitetônicas específicas, como eixos de visão desimpedidos e amplos para circulação; espaço para comunicação gestual; sinalização adequada, objetiva e de compreensão acessível; aberturas e/ou transparências entre ambientes e entre desníveis; preferência por rampas ao invés de escadas; redução de ruídos e reverberação; proteção contra ofuscamento da iluminação; arranjos flexíveis do mobiliário; uso de cores, contrastes e superfícies reflexivas (Figura 09); soluções luminosas para avisos tradicionalmente sonoros, dentre outras diretrizes.

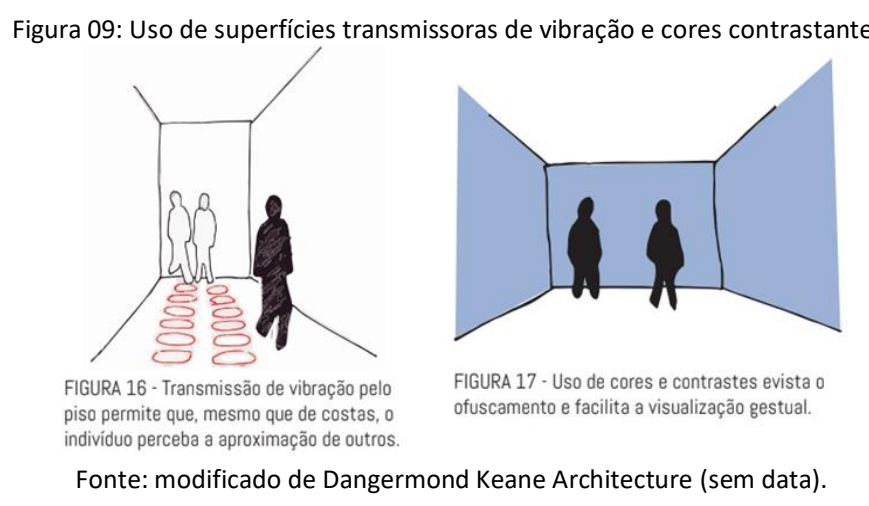

Por fim, buscou-se criar entre texto e imagem uma relação de complementação, nunca de repetição ou exclusão (Figura 10). Assim como as figuras, o texto tem linguagem simplificada, direta e objetiva, visando transmitir o conteúdo de forma clara e fácil.

Figura 10: Aberturas internas e privacidade / Complementação entre texto e imagem.

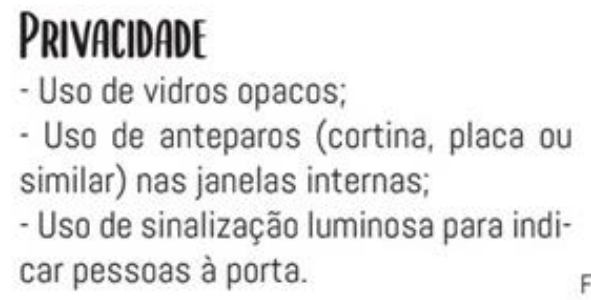

Fonte: modificado de Sangalang (2012)

Um último tópico apresenta Observações Gerais, onde são abordadas as necessidades de complementar o projeto com elementos de wayfinding gráfico, que pode ser representado através de placas de sinalização, luzes de emergências, alarmes sonoros visuais.

A cartilha finaliza com as Considerações Finais e Referências Bibliográficas, para auxiliar os leitores em novas consultas e pesquisas. Nas Considerações Finais é inserido um texto que descreve a necessidade de implementar melhorias na qualidade de ensino e a valorização da atuação multidisciplinar do arquiteto, em todo o processo de projeto (KOWALTOWSKI et al,2011c), ressaltando que cada projeto tem sua peculiaridade e cada usuário tem suas características e necessidades únicas, cabendo portanto ao arquiteto buscar a melhor forma de coordenar e propor soluções para a acessibilidade. 


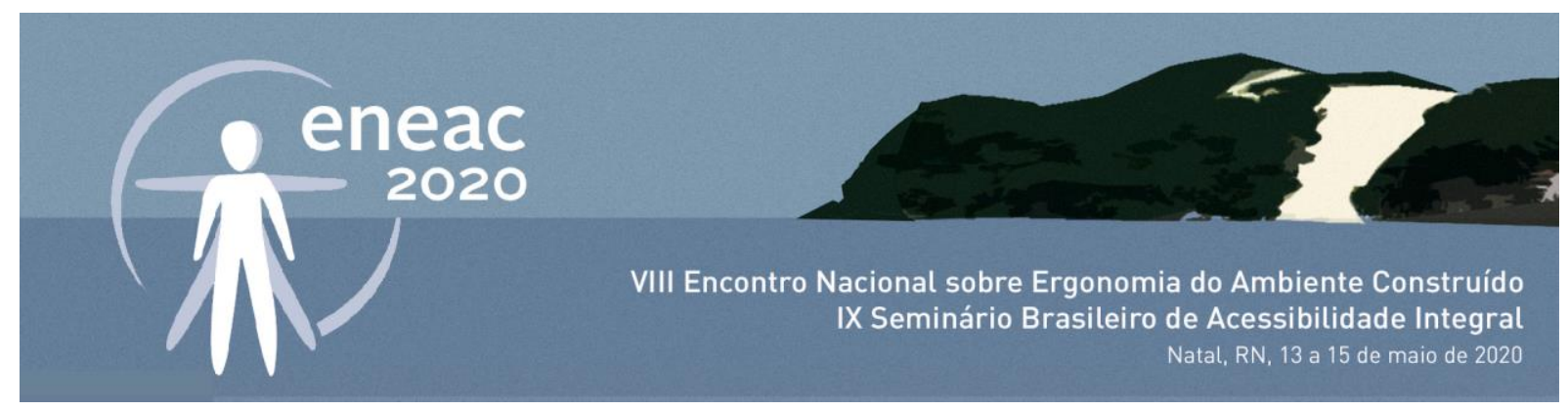

As soluções são genéricas, de modo que podem ser aplicadas em diversos espaços. Contudo, cabe destacar que nenhuma diretriz apresentada pela cartilha exclui ou se sobrepõe às normas vigentes ou à análise singular de cada ambiente caso a caso. A "Cartilha de Acessibilidade para Deficientes Auditivos em Ambiente Escolar: orientações para arquitetos" pode ser apreciada na íntegra acessando o link https://www.flipsnack.com/B7A87BA7C6F/cartilha-de-acessibilidade-paradeficientes-auditivos-em-amb.html.

\section{DISCUSSÃO}

Diante da escassez de literatura sobre o tema e de situações inadequadas criadas pelos limites máximos e mínimos das normas que por vezes são obedecidas com pouco bom senso, o presente trabalho visa apresentar um panorama de possibilidades pouco conhecidas para a produção de espaços mais adequados para os deficientes auditivos.

A partir da revisão bibliográfica da literatura encontrada, os conceitos de Desenho Universal, DeafSpace, Well Building e wayfinding foram adotados como parâmetros importantes para se projetar ambientes para este público. Experiências demonstram que tais conceitos são tão pouco difundidos, inclusive entre os profissionais de arquitetura, que por vezes as soluções causam estranhamento até mesmo para os deficientes auditivos, que mais poderiam usufruir delas (MEDEIROS E ELALI, 2018). Contudo, nota-se que boa parte das soluções, se aplicadas corretamente, poderiam beneficiar a todos os usuários do espaço, deficientes ou não (TSYMBAL, 2010).

No ambiente escolar, o projeto KVA para o concurso "Shape Gallaudet", bem como os demais casos apresentados pela bibliografia encontrada, evidenciam algumas soluções de projeto em comum que contemplam algumas das necessidades particulares dos deficientes auditivos. Destacam-se: conectividade visual dos ambientes (uso de transparências, superfícies reflexivas, aberturas internas, átrios, vidro fosco); circulação desimpedida (caminhos mais largos, previsão de nichos para aglomerações, cantos arredondados); espaços de estar coletivo (espaço e mobiliário adequados para a comunicação gestual); controle de iluminação e ofuscamento; experiências sensoriais (vibração e iluminação substituindo sinalizações tradicionalmente sonoras); disposição flexível do mobiliário.

A partir das soluções encontradas, utilizou-se os conceitos apreendidos da análise iconográfica de cartilhas existentes para a produção desta "Cartilha de Acessibilidade para Deficientes Auditivos em Ambiente Escolar: orientações para arquitetos". A cartilha não substitui a vigência das normas de acessibilidade, nem tampouco exclui a necessidade de se avaliar os espaços e necessidades individualmente a cada caso. Cabe ao profissional encontrar o equilíbrio entre os conceitos e as necessidades do usuário e entender como colocá-los no ambiente. Em dois casos estudados (MEDEIROS E ELALI, 2018 e JOHNSON, 2014), a aplicação prática dos conceitos foi questionada pelos deficientes auditivos, que argumentaram que, apesar de entenderem e concordarem com seu objetivo, consideravam que, em seu caso particular, tais conceitos não se aplicam.

A proposta da cartilha é apresentar aos profissionais de arquitetura os conceitos básicos utilizados no presente trabalho (Desenho Universal, DeafSpace, Well Building e wayfinding) e, a partir deles, sugerir soluções genéricas, aplicáveis a diferentes espaços, para aprimorar a vivência dos surdos e deficientes auditivos no ambiente da escola. 


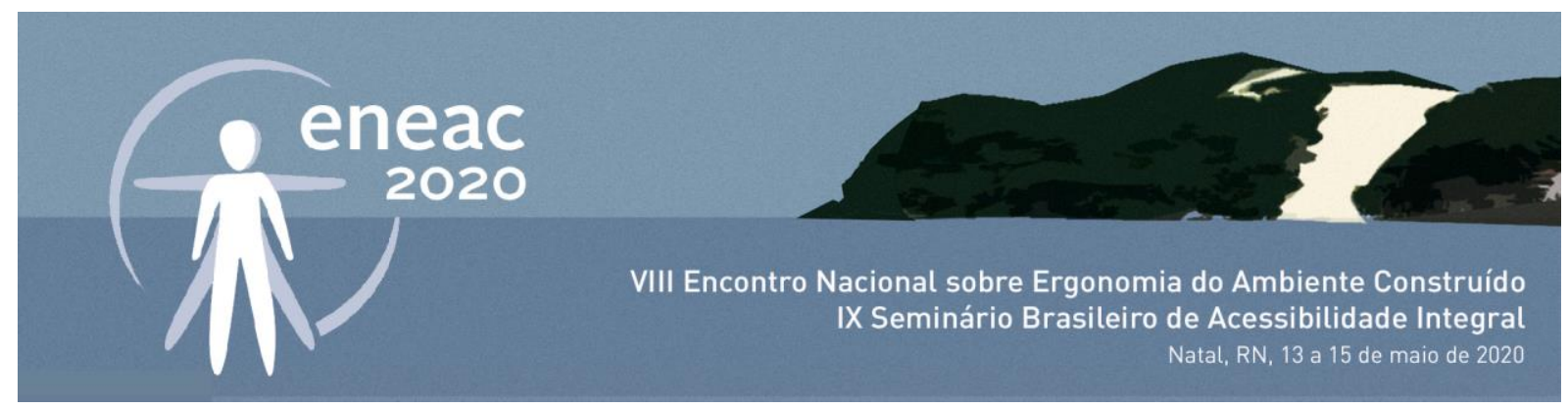

\section{REFERÊNCIAS}

BAUMAN, H. Deafspace Design Guideline, Working Draft. Washington, DC: Gallaudet University. 2010.

BRASIL. Decreto no 5296 de 2 de dezembro de 2004 . Disponível em: <http://www.planalto.gov.br/ccivil_03/_ato20042006/2004/decreto/d5296.htm> Acesso em 10/06/2019.

DANGERMOND S.; KEANE C. DeafSpace design guidelines.(sem data). Dangermond Keane Architecture. Disponível em <http://dangermondkeane.com/projects/deafspace-design-guide> Último acesso em 10/janeiro/2020

FRANSOLIN, L. C.; RODRIGUES, J. C.; ANTONINI, B.; BERNARDI, N.; KOWALTOWSKI, D. C. C. K. O jogo da arquitetura: discutindo a acessibilidade para surdos. ENEAC, 2016.

FNDE (Fundo Nacional de Desenvolvimento da Educação). Elaboração de projetos de edificações escolares: Ensino Fundamental Manual de orientações técnicas. Volume 3. (em desenvolvimento). Disponível em

<http://www.fnde.gov.br/index.php/programas/proinfancia/areas-para-gestores/manuais?limitstart=0 $>$. Último acesso em 06/maio/2019.

FNDE (Fundo Nacional de Desenvolvimento da Educação). Manual técnico de arquitetura e engenharia de orientação para elaboração de projetos de construção de centros de educação infantil. 2009. Disponível em <http://ftp.fnde.gov.br/web/pro_infancia/cartilha_proinfancia_projetos_proprios.pdf>. Último acesso em 10/maio/2019.

GALLAUDET UNIVERSITY. International Design Competition, 2016. Disponível em <https://competitions.malcolmreading.com/gallaudet/competition>. Último acesso em 20/janeiro/2020.

JOHNSON, C. A. Articulation of deaf and hearing spaces using deafspace design guidelines: A community based participatory research with the Albuquerque sign language academy, 2010. Disponível em <https://digitalrepository.unm.edu/arch_etds/18>. Último acesso em 10/junho/2019.

KOWALTOWSKI, D. C. C. K., BIANCHI, G.; PETRECHE, J. R. D. A criatividade no processo de projeto. O processo de projeto em arquitetura. ed. Oficina de Textos, Cubatão, S.P., 2011 a.

KOWALTOWSKI, D. C. C. K. Arquitetura escolar: o projeto do ambiente de ensino. ed. Oficina de Textos, Cubatão, S.P., 2011b

KOWALTOWSKI, D. C. C. K.; DELIBERADOR, M. S.; PEREIRA, P. R. P.; GRAÇA, V. A. C. Arquitetura escolar e seu processo de projeto. O processo de projeto em arquitetura. ed. Oficina de Textos, Cubatão, S.P. 2011c.

MEDEIROS, A. T. F.; ELALI, G. A. A percepção de surdos como subsídio ao projeto: um estudo com o uso de maquete física. ENEAC, 2018

NAIR, P.; FIELDING, R. I. A Comfortable Truth: Well-Planned Classrooms Make a Difference. 2007. Disponível em <https://www.edutopia.org/comfortable-truth>. Último acesso em 10/junho/2019.

NEVES, R. A.; NEVES, A. S. O. A importância da ergonomia do ambiente construído nos projetos arquitetônicos - o caso dos deficientes auditivos ENEAC, 2016.

SANGALANG, J. What is Privacy in Deaf Space? Thesis - American Sign language and deaf studies department, Gallaudet University, Washington, DC, 2012. Disponível em <https://deafgeografies.files.wordpress.com/2014/sangalang.jordan what is privacy in deafspace final print copy-libre.pdf $>$ Último acesso em 05/junho/2019.

SASSAKI, Romeu Kazumi. Inclusão: acessibilidade no lazer, trabalho e educação. Revista Nacional de Reabilitação (Reação), São Paulo, Ano XII, mar./abr. 2009, p. 10-16. Disponível em: <https://acessibilidade.ufg.br/up/211/o/SASSAKI_-

Acessibilidade.pdf?1473203319>. Acesso em: 19 jun. 2019.

SILINGARDI, A. A. T.; AVEIRO, M. G. Cartilha de Acessibilidade para Deficientes Auditivos em Ambiente Escolar - orientações para arquitetos. Disciplina AQ050 Desenho Universal no Projeto Arquitetônico. Programa de Pós-graduação em Arquitetura, Tecnologia e Cidade. Universidade Estadual de Campinas, 2019. Disponível no link : https://www.flipsnack.com/B7A87BA7C6F/cartilha-de-acessibilidade-para-deficientes-auditivos-em-amb.html

TSYMBAL, K. A. Deaf space and the visual world - Buildings that speak: an elementary school for the deaf. 2010. Disponível em <https://drum.lib.umd.edu/handle/1903/11295>. Último acesso em 27/maio/2019. 